\title{
KRAS Mutation Analysis
}

National Cancer Institute

\section{Source}

National Cancer Institute. KRAS Mutation Analysis. NCI Thesaurus. Code C79418.

A procedure to test for the presence of mutations in the KRAS gene. 